\title{
Analysis of a Permo-Triassic polarity transition in different absolute reconstructions of Pangaea, considering a model with features of the present Earth magnetic field
}

\author{
Haroldo Vizán and María Andrea Van Zele \\ Consejo Nacional de Investigaciones Científicas y Técnicas (CONICET) and Departamento de Ciencias \\ Geológicas, Facultad de Ciencias Exactas y Naturales, Universidad de Buenos Aires, Argentina
}

\begin{abstract}
The main objective of this paper is to show that the distribution of transitional palaeomagnetic data recorded at $250 \mathrm{Ma}$ are in agreement with simulated data that depend on the sampling site, using a model that considers features of the Present Earth magnetic field. The analysis was performed comparing simulated reversals with the Permo-Triassic polarity transition recorded in the Siberian Trap Basalts. The palaeomagnetic data were corrected according to the Palaeo-latitude and Palaeo-longitude of Siberia (absolute reconstruction) at 250 Ma using hotspot tracks. To obtain the motion of Siberia relative to hotspots from the Present time back to $250 \mathrm{Ma}$, three different Pangaea models were considered (Pangaea A, Pangaea A2, Pangaea B). In spite of the uncertainties associated with the use of hotspot frameworks and Pangaea configurations, both the modelled and recorded data show a remarkable fit when absolute reconstructions of Pangaea A and A2 configurations are performed. The agreement between both simulated and recorded data suggests that similar features to that of the Present Earth magnetic field could have been involved in reversals since the Permo-Triassic.
\end{abstract}

Key words Permo-Triassic - Pangaea - absolute reconstruction - Earth magnetic field - polarity transition

\section{Introduction}

Different rock types are capable of recording the directions of the Earth's Magnetic Field

Mailing address: Dr. Haroldo Vizán, Consejo Nacional de Investigaciones Científicas y Técnicas and Departamento de Ciencias Geológicas, Facultad de Ciencias Exactas y Naturales, Universidad de Buenos Aires, Intendente Güiraldes 2160, Ciudad Universitaria, Pabellón II, 1er piso, C1428EGA Buenos Aires, Argentina; e-mail: haroldo@gl.fcen.uba.ar
(EMF). Through these records, we know that the dipolar component of the geomagnetic field periodically inverts its polarity. Our knowledge on what happens as the field reverses comes from the evaluation of transition palaeomagnetic records. The earliest analysis of geomagnetic polarity reversals was that determined for the Jurassic Stormberg volcanic rocks of Lesotho in Southern Africa (van Zijl et al., 1962). However, most studies of this intriguing process of the EMF have used Cainozoic data (see Coe and Glen, 2004), because transitional records are difficult to determine in older lithologies; as these rocks have probably undergone more geological processes that resulted in remagnetizations resetting total or partially the original data. 
On the other hand, for all of geological time (including the Cainozoic) transition records depend on the capabilities of rocks to act as natural magnetic recorders. Lava flows are considered to record the most accurate spot readings of the geomagnetic field (Hoffman, 1992) but due to the episodic nature of eruptions, their transition records can be discontinuous or multiple lava flows can be emplaced over a shorter time span compared with the rate of variation of the EMF, in which case the flows will preserve redundant records of this field (Prévot and Camps, 1993). Sedimentary rock sequences can be quasi-continuous records but they become magnetized by physical and chemical processes of relatively long duration that occur from the deposition of the sediment till the diagenesis. Magnetic directions of sedimentary rocks considered as transitional records could be, indeed, artefacts and not real readings of the EMF (Langereis et al., 1992).

In spite of these problems, longitudinal confinements of Virtual Geomagnetic Poles (VGPs) of Cainozoic transitional records were interpreted as representative of geomagnetic behaviours (Clement, 1991; Laj et al., 1991; Hoffman, 1992; Love, 1998) and different geodynamo models have been suggested to explain Cainozoic polarity transitions. Hoffman (1992) has suggested that inclined dipolar reversal states of the EMF have dominated Cainozoic reversals. Gubbins and Coe (1993) and Gubbins (1994) provided an explanation to link longitude-confined VGP paths to variations in the magnetic flux on the Earth's core surface based on a model proposed by Gubbins (1987). Glatzmaier et al. (1999) simulated a suite of reversals which examples were presented by Coe et al. (2000); the most interesting of these simulated reversals is that produced by the tomographic geodynamo model where the heat-flux at the core-mantle boundary is patterned on the large-scale variation of seismic velocity from tomographic studies of the lowermost mantle.

As indicated above, transition records for reversals older than the Cainozoic are much more difficult to determine and there are no specific models to explain the polarity transitions of the EMF during the Mesozoic or Palaeozoic times. However, reliable transition records of those times can be analyzed considering the models proposed for the Cainozoic and then, speculate about the mechanisms that manage Mesozoic or Palaeozoic reversals.

A recent study by Heunemann et al. (2004) provided reliable directions and intensities for a reversal of the EMF recorded in the Permo-Triassic (ca. $250 \mathrm{Ma}$ ) Siberian Trap Basalts. Heunemann et al. (2004) corrected the corresponding VGPs of the recorded directions for a Permo-Triassic palaeo-geography of Siberia and invoked two alternatives, based on the models presented by Coe et al. (2000) and Hoffman (1992), to account for the characteristic features observed in their data. It is noteworthy that the Euler rotation pole used by Heunemann et al. (2004) is just to determine the Palaeo-latitude of Siberia at 250 Ma (Smethurst et al., 1998) but not the palaeolongitude of this continental block at that age.

This paper compares simulated reversals determined by the model proposed by Gubbins (1994) with the Permo-Triassic polarity transition recorded in the Siberian Trap Basalts. Palaeomagnetic data were corrected in accordance with the Palaeo-latitude and Palaeo-longitude of Siberia at $250 \mathrm{Ma}$ using hotspot tracks as has been done for the analysis of the Jurassic transition recorded in the Stormberg Lavas (Vizán and Van Zele, 1995; Prévot et al., 2003). To obtain the motion of Siberia relative to hotspots from the Present back to $250 \mathrm{Ma}$, several relative reconstructions from a variety of sources were used assuming that three different models of Pangaea are valid for $250 \mathrm{Ma}$ (Pangaea A, Pangaea A2, Pangaea B). Remarkable agreements between the simulated and recorded transitional data were obtained after latitude and longitude palaeo-geographic corrections, especially if Pangaea A and A2 models were used.

\section{Discussion on the data and methodologies}

The analyzed palaeomagnetic data were compiled from table 2 of Heunemann et al. (2004). The extremely high lava productivity makes the Siberian Trap Basalts a possible continuous record for the palaeo-directions of the EMF. According to Heunemann et al. (2004) its stratigraphically lower section contains three 
successive flows of reversed polarity followed by flows that record a transitional state of the EMF. The upper section shows normal polarity and a group of directions that is tentatively interpreted by Heunemann et al. (2004) as an excursion. Analysis in this paper concentrates on data that record the transitional state (considering also those three data of reverse polarity in the lower section and some of normal polarity of the upper section). Data belonging to the possible excursion as interpreted by the same authors were not analyzed. The transitional record shows a clustering of data that may be explained as a rapid succession of lava flows; however the palaeo-intensity results indicate that this phenomenon has a geomagnetic cause as several independent field states are recorded (Huenemann et al., 2004).

This paper uses the geomagnetic polarity reversals mechanism proposed by Gubbins (1994) to analyze the transitional record of the Siberian Trap Basalts, because it is based on the configuration of EMF at the core surface derived from historical records (Gubbins, 1987) and has the interesting feature that for the same reversal, different paths of VGPs are predicted at different measurement sites (see Gubbins, 1994; his figs. 12 and 13). The present work analyses whether the VGPs simulated by Gubbins' model are comparable to the cluster of VGPs recorded in the location of the Siberian Trap Basalts at about $250 \mathrm{Ma}$.

Hotspot models were used to determine palaeo-latitudinal and palaeo-longitudinal corrections in our analysis. Whether hotspots move slowly enough with respect to one another to provide a useful reference frame to make absolute reconstructions has been the subject of discussion (i.e. Torsvik et al., 2002). For some workers hotspot models are not very reliable, but others use them in tectonics and geomagnetic models. Absolute reconstructions, for the last $120 \mathrm{Ma}$, for Africa based on a moving hotspot reference frame, have been recently suggested by O'Neill et al. (2005) Many tectonics and geomagnetism studies (i.e. Engebretson et al., 1985; Besse and Courtillot, 2002; Prévot et al., 2003) have used an earlier model that considered that hotspots are reasonably fixed and form a convenient reference frame to determine $a b-$ solute motions of Africa for the last $200 \mathrm{Ma}$ (Morgan, 1983). Hotspot tracks have been recognized by Zonenshain et al. (1985) to calculate a clockwise rotation of Siberia from 130 to 280 Ma. This paper used all three of these hotspot models and also determined if an absolute reconstruction of the sampling site based on these models, gives a better agreement between simulated and recorded data.

In order to determine the motion of the sampling site with respect to the hotspots it is necessary to perform a relative reconstruction of Eurasia with Africa at Present geographic coordinates using a reconstruction of Pangaea at $250 \mathrm{Ma}$. However, after more than 25 years of discussions among palaeomagnetists, there is no general consensus about the configuration of Pangaea during the Late Palaeozoic-Early Mesozoic. It is generally agreed that the Pangaea configuration proposed by Wegener (1922), named Pangaea A and quantified by Bullard et al. (1965), was the starting point for the break up of this super continent in the Middle Jurassic. However, Palaeomagnetic Poles (PPs) of Gondwana and Laurasia for the Late Carboniferous to Middle Triassic cannot be reconciled with this reconstruction and show a systematic discrepancy that could be due to different factors such as inclination shallowing in sediments, unrecognized overprints that have not been removed during demagnetization, underestimation of rock ages (Rochette and Vandamme, 2001; McElhinny, 2004; Van der Voo and Torsvik, 2004). This systematic misfit between PPs has also been interpreted in geodynamic or geomagnetic terms. Briden et al. (1971), Van der Voo and Torsvik (2001) and Torsvik and Van der Voo (2002) propose that a possible explanation for this disagreement is the existence of persistent non-dipolar (octupolar) fields. Many other workers have invoked different reconstructions of Pangaea called Pangaea B (i.e. Morel and Irving, 1981; Torcq et al., 1997; Muttoni et al., 2003; Rakotosolofo et al., 2005) and Pangaea A2 (i.e. Van der Voo and French, 1974; Van der Voo et al., 1976; Smith and Livermore, 1991) to produce an agreement between the Laurasia and Gondwana PPs. Pangaea A2 is not very different from Pangaea A and the transition of one to another, involves a small dextral mega shear of about $500 \mathrm{~km}$ but the transforma- 
tion of Pangaea B to Pangaea A involves a large dextral mega shear (of 4000-3500 km). Muttoni et al. (1996) proposed the evolution of Pangaea from Pangaea B to A2 during the mid-Permian and from A2 to A during the Late Triassic.

The polarity transition analysis presented here also determined which Pangaea model gives the better agreement between the transition data produced using the Gubbins (1994) model and the data recorded from the Siberian Trap Basalts.

\section{Palaeoreconstructions of the palaeomagnetic data recorded in Siberian Trap Basalts}

The sections studied by Heunemann et al. (2004) are located in the Listvjanka $\left(69^{\circ} 28^{\prime} \mathrm{N}\right.$, $88^{\circ} 43^{\prime} \mathrm{E}$ ) and Icon/Abagalakh river valleys $\left(70^{\circ} 22^{\prime} \mathrm{N}, 90^{\circ} 04^{\prime} \mathrm{E}\right)$. For the present study the geographic localities were averaged and the palaeomagnetic data were normalised to $69^{\circ} 55^{\prime} \mathrm{N}$, $89^{\circ} 23^{\prime} \mathrm{E}$. The geographic coordinates of this locality in the Permo-Triassic were determined from a mean Siberian Trap PP using the different models of Pangaea and hotspot frameworks mentioned above.
We considered a PP that is the mean of four entries as a representative pole position for the Siberian Trap Basalts. The four entries are 1) a mean Siberian Trap pole at $54.7^{\circ} \mathrm{N} / 140.5^{\circ} \mathrm{E}$ given in Torsvik and Andersen (2002); 2) Global Palaeomagnetic Database (GPMDB)-REFNO $2832\left(59^{\circ} \mathrm{N} / 150^{\circ} \mathrm{E}\right)$, see also Gurevitch et al. (1995); 3) a pole from Gurevitch et al. (2004: $\left.54.6^{\circ} \mathrm{N} / 146^{\circ} \mathrm{E}\right)$; 4) a pole from Heunemann et al. (2004: $57.1^{\circ} \mathrm{N} / 148.2^{\circ} \mathrm{E}$ ). The geographic coordinates and the Fisherian statistical parameters of the mean PP are: Lat $=56.4^{\circ} \mathrm{N}$, Long $=$ $=146.0^{\circ} \mathrm{E}, \mathrm{A} 95=3.5^{\circ}, \mathrm{K}=677.9$. This mean PP is quite similar to that obtained with 3 entries by Van der Voo and Torsvik (2004) for the Siberian Traps $\left(\right.$ Lat $=56^{\circ} \mathrm{N}$, Long $\left.=150^{\circ} \mathrm{E}, \mathrm{A} 95=6^{\circ}\right)$. In our case the mean PP includes the pole yielded by the stable reverse and normal directions of the sections that recorded the transition (Heunemann et al., 2004) and then the A95 is reduced from $6^{\circ}$ to $3.5^{\circ}$.

Recently Van der Voo and Torsvik (2004) compared their mean Siberian Trap pole with the mean Gondwana PP for $250 \pm 10 \mathrm{Ma}$ of Torsvik and Van der Voo (2002) in a Pangea A configuration assuming that Siberia formed part of Eurasia at ca. $250 \mathrm{Ma}$ (Smethurst et al., 1998;

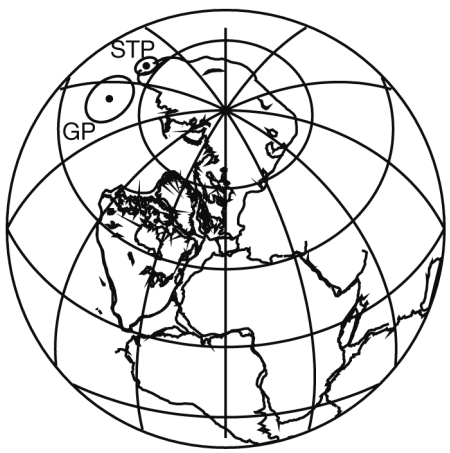

Pangaea A

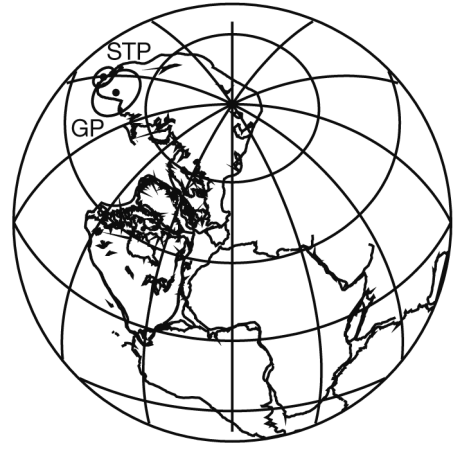

Pangaea A2

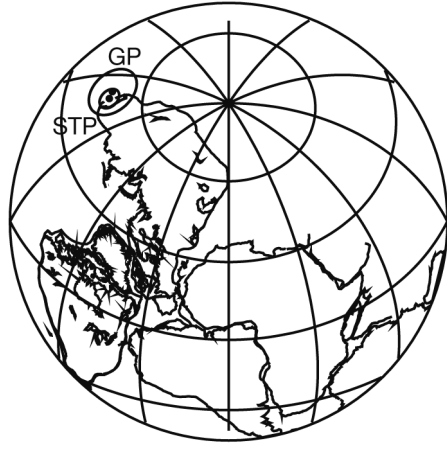

Pangaea B

Fig. 1a-c. Comparison of Gondwana mean palaeopole (GP) for $250 \pm 10 \mathrm{Ma}$ and Siberian Trap mean palaeopole (STP) in different Pangaea reconstructions with Central Africa held fixed at present geographic coordinates. a) Pangaea A model, notice the discrepancy between the mean palaeopoles. b) Pangaea A2 model, the mean palaeopoles are indistinguishable at $95 \%$ of confidence level, although there is a great circle distance of about $9^{\circ}$ between them. c) Pangaea B model, the mean palaeopoles get the better fit. A supposed mega-shear of about $3700 \mathrm{~km}$ is required to pass from this Pangaea configuration to a Pangaea A model (the starting point of the break up of this super-continent during Middle Jurassic time). 
Table I. Rotation poles for the sampling site in Pangaea A model.

\begin{tabular}{lcccc}
\hline \hline \multicolumn{1}{c}{ Euler pole } & Latitude $\left({ }^{\circ} \mathrm{N}\right)$ & Longitude $\left({ }^{\circ} \mathrm{E}\right)$ & Rotation (degree) & Reference \\
\hline $\begin{array}{l}\text { 1) Eurasia relative } \\
\text { to North America }\end{array}$ & 88.5 & 27.7 & -38 & Bullard et al. $(1965)$ \\
$\begin{array}{l}\text { 2) North America relative } \\
\text { to NW Africa }\end{array}$ & 66.95 & -12.02 & 75.55 & Klitgord and Schouten (1986) \\
$\begin{array}{l}\text { 3) NW Africa relative } \\
\text { to Central Africa }\end{array}$ & 12.23 & 19.01 & 3.44 & Schettino and Scotese (2005) \\
$\begin{array}{l}\text { 4) Africa relative to hotpots } \\
\quad(0 \text { to } 120 \mathrm{Ma})\end{array}$ & 17.03 & -27 & -29.72 & O'Neill et al. $(2005)$ \\
$\begin{array}{l}\text { 5) Africa relative to hotpots } \\
\quad(120 \text { to } 200 \mathrm{Ma})\end{array}$ & 31.38 & 3.4 & 32.18 & Morgan $(1983)\left(^{*}\right)$ \\
$\begin{array}{l}\text { 6) Eurasia relative to hotspots } \\
(200 \text { to } 250 \mathrm{Ma})\end{array}$ & 85.03 & 252.46 & 25 & Zonenshain et al. $(1985)\left(^{* * *}\right)$ \\
7) True Polar Wander & 0 & 187.46 & 28.15 & $\left(^{* * *}\right)$
\end{tabular}

(*) Stage pole calculated using the Euler poles of 120 Ma and 200 Ma of Morgan (1983).

$\left(^{* *}\right)$ The geographic coordinates of this Euler pole (now at $54^{\circ} \mathrm{N}, 104^{\circ} \mathrm{E}$ ) were calculated for $200 \mathrm{Ma}$ in Pangaea A model.

$\left({ }^{* * *}\right)$ Rotation about an equatorial Euler pole to account for the displacement of the rotation (palaeomagnetic) axis with respect to core/mantle boundary (Cox and Hart, 1986).

Torsvik et al., 2001). Van der Voo and Torsvik (2004) noted that using these poles there is still a continental overlap of $1000 \mathrm{~km}$ if Pangea A is used.

This paper also compare the new Siberian Trap mean PP with a Gondwana PP for 250 $\mathrm{Ma} \pm 10 \mathrm{Ma}$ in three models of Pangea (A, A2 and $\mathrm{B}$, see fig. 1a-c). Thirteen poles for the stable parts of Gondwana continents compiled by Torsvik and Van der Voo (2002) were combined with the reconstruction parameters for Gondwana continents recently proposed by Schettino and Scotese (2005). These new reconstruction parameters were used noting that Torsvik and Van der Voo (2002) were not entirely satisfied with published Gondwana fits. The resulting mean Gondwana PP in Present Central Africa geographic coordinates is based on a conventional Fisherian calculation; its geographic coordinates and statistical parameters are: Lat $=$ $=48.4^{\circ} \mathrm{N}$, Long $=249.3^{\circ} \mathrm{E}, \mathrm{A} 95=8.4^{\circ}, \mathrm{K}=25.6$.

The comparison was made with Central Africa held fixed and transferring the Siberian Trap pole to the geographic coordinates of this continental block through a plate circuit (Euler poles 1, 2 and 3 in table I). The first rotation of the Siberian Trap pole was to reconstruct the continent of Laurasia «closing» the north Atlantic through the movement of Eurasia towards North America. For this reconstruction the Bullard et al. (1965) Euler pole was used because Van der Voo (1990) and Torsvik et al. (2001) have demonstrated that this reconstruction gives best agreement between Late Carboniferous-Late Triassic European and North American PPs. The second rotation of the Siberian Trap pole used the reconstruction parameter of Klitgord and Schouten (1986) from North America to northwest Africa, which belongs to a model of Pangaea A. Finally the pole was transferred from northwest Africa to Central Africa using the reconstruction parameters of Schettino and Scotese (2005). Figure 1a shows Gondwana and Siberian Trap PPs in Central Africa geographic coordinates using the Pangaea A configuration. The PPs do not fit, they are distinguishable at $95 \%$ of confidence level and the great circle distance between them is of $15.2^{\circ}$.

To compare both mean PPs with a model of Pangaea A2, the Siberian Trap pole was rotated using also the finite pole of rotation of Van der Voo and French (1974) «closing the Gulf of 
Table II. Rotation poles for the sampling site in Pangaea A2 model.

\begin{tabular}{|c|c|c|c|c|}
\hline Euler pole & Latitude $\left({ }^{\circ} \mathrm{N}\right)$ & Longitude $\left({ }^{\circ} \mathrm{E}\right)$ & Rotation (degree) & Reference \\
\hline $\begin{array}{l}\text { 1) Eurasia relative } \\
\text { to North America }\end{array}$ & 88.5 & 27.7 & -38 & Bullard et al. (1965) \\
\hline $\begin{array}{l}\text { 2)North America relative } \\
\text { to NW Africa }\end{array}$ & 66.95 & -12.02 & 75.55 & Klitgord and Schouten (1986) \\
\hline $\begin{array}{l}\text { 3) NW Africa relative } \\
\text { to Central Africa }\end{array}$ & 12.23 & 19.01 & 3.44 & Schettino and Scotese (2005) \\
\hline $\begin{array}{l}\text { 4) Rotation to close } \\
\text { the Gulf of Mexico }\end{array}$ & 17.38 & -8.91 & 16.13 & Van der Voo and French (1974) $\left(^{*}\right)$ \\
\hline $\begin{array}{l}\text { 5) Africa relative to hotpots } \\
\text { (0 to } 120 \mathrm{Ma})\end{array}$ & 17.03 & -27 & -29.72 & O’Neill et al. (2005) \\
\hline $\begin{array}{l}\text { 6) Africa relative to hotpots } \\
\text { (120 to } 200 \mathrm{Ma})\end{array}$ & 31.38 & 3.4 & 32.18 & Morgan $(1983)\left(^{* *}\right)$ \\
\hline $\begin{array}{l}\text { 7) Eurasia relative to hotspots } \\
\text { (200 to } 250 \mathrm{Ma})\end{array}$ & 69.17 & 268.5 & 25 & Zonenshain et al. (1985) $\left(^{(* * *}\right)$ \\
\hline 8) True Polar Wander & 0 & 187.03 & 44.17 & $(* * *)$ \\
\hline
\end{tabular}

(") Re-calculated considering the reconstruction parameter of Klitgord and Schouten (1986) for North America relative to NW Africa and the rotation parameter of Schettino and Scotese (2005) for NW Africa relative to Central Africa.

$\left(^{* *}\right)$ Stage pole calculated using the Euler poles of 120 Ma and 200 Ma of Morgan (1983).

$\left.{ }^{(* * *}\right)$ The geographic coordinates of this Euler pole (now at $54^{\circ} \mathrm{N}, 104^{\circ} \mathrm{E}$ ) were calculated for $200 \mathrm{Ma}$ in Pangaea A2 model.

${ }^{(* * * *)}$ Rotation about an equatorial Euler pole to account for the displacement of the rotation (palaeomagnetic) axis with respect to core/mantle boundary (Cox and Hart, 1986).

Mexico». Figure $1 \mathrm{~b}$ shows the PPs of Gondwana and Siberian Traps transferred to Central Africa geographic coordinates (Euler poles 1,2, 3 and 4 in table II) in a Pangaea A2 configuration. The great circle distance between the mean PPs is of $9.1^{\circ}$; however there is an overlap between the $95 \%$ confidence level intervals and the 4 poles of Siberian Trap Basalts share a common mean at $95 \%$ confidence (McFadden and Lowes, 1981) with Gondwana PPs.

To compare Gondwana and Siberian Trap mean PPs with a model of Pangaea B, a finite pole of rotation to obtain the motion of North America relative to Central Africa was calculated using the analysis of Morel and Irving (1981) and the reconstruction parameters of Klitgord and Schouten (1986) and Schettino and Scotese (2005). This rotation parameter has its pole at Lat $=36.2^{\circ} \mathrm{N}$, Long $=04.0^{\circ} \mathrm{W}$, and an angle of rotation $=77.35^{\circ}$ (counter clockwise). The relative position between the Atlantic bordering continents obtained with this reconstruction parameter is shown in fig. 1c together with Gondwana and the Siberian Trap mean PPs transferred to Central Africa geographic coordinates (Euler poles 1, 2, 3 and 4 in table III). The great circle distance between these PPs is $2.5^{\circ}$ and, obviously, they are undistinguishable at $95 \%$ of confidence level.

To perform our transition record analysis, absolute reconstructions of the sampling site were made by considering the Siberian Trap mean PP (as representative of the palaeomagnetic spin axis at $250 \mathrm{Ma}$ ), different models of Pangaea and the hotspot frameworks already mentioned.

Firstly we transferred the Siberian Trap mean PP to Present Central Africa coordinates using the reconstruction parameters to build the different models of Pangaea. After that, we rotated the plates and the pole position according to the Euler pole of O'Neill et al. (2005) for $120 \mathrm{Ma}$. Then again we rotated the plates and the pole po- 
Table III. Rotation poles for the sampling site in Pangaea B model.

\begin{tabular}{|c|c|c|c|c|}
\hline Euler pole & Latitude $\left({ }^{\circ} \mathrm{N}\right)$ & Longitude $\left({ }^{\circ} \mathrm{E}\right)$ & Rotation (degree) & Reference \\
\hline $\begin{array}{l}\text { 1) Eurasia relative } \\
\text { to North America }\end{array}$ & 88.5 & 27.7 & -38 & Bullard et al. (1965) \\
\hline $\begin{array}{l}\text { 2) North America relative } \\
\text { to NW Africa }\end{array}$ & 66.95 & -12.02 & 75.55 & Klitgord and Schouten (1986) \\
\hline $\begin{array}{l}\text { 3) NW Africa relative } \\
\text { to Central Africa }\end{array}$ & 12.23 & 19.01 & 3.44 & Schettino and Scotese (2005) \\
\hline $\begin{array}{l}\text { 4) Transition from Pangaea } \\
\text { A to B }\end{array}$ & -25.79 & 47.49 & 35.79 & Morel and Irving (1981) $\left(^{*}\right)$ \\
\hline $\begin{array}{l}\text { 5) Africa relative to hotpots } \\
\text { (0 to } 120 \mathrm{Ma} \text { ) }\end{array}$ & 17.03 & -27 & -29.72 & O’Neill et al. (2005) \\
\hline $\begin{array}{l}\text { 6) Africa relative to hotpots } \\
\text { (120 to } 200 \mathrm{Ma})\end{array}$ & 31.38 & 3.4 & 32.18 & Morgan $(1983)\left(^{* *}\right)$ \\
\hline $\begin{array}{l}\text { 7) Eurasia relative to hotspots } \\
\text { (200 to } 250 \mathrm{Ma})\end{array}$ & 59.77 & 314.62 & 25 & Zonenshain et al. $(1985)\left(^{* * *}\right)$ \\
\hline 8) True Polar Wander & 0 & 198.77 & 47.9 & $(* * * *)$ \\
\hline
\end{tabular}

(*) Re-calculated considering the reconstruction parameter of Klitgord and Schouten (1986) for North America relative to NW Africa and the rotation parameter of Schettino and Scotese (2005) for NW Africa relative to Central Africa. The motion of North America relative to Central Africa in a Pangaea B model can be determined through a cumulative rotation including the reconstruction parameters 2), 3) and 4).

$\left(^{* *}\right)$ Stage pole calculated using the Euler poles of $120 \mathrm{Ma}$ and $200 \mathrm{Ma}$ of Morgan (1983).

$\left({ }^{* * *}\right)$ The geographic coordinates of this Euler pole (now at $54^{\circ} \mathrm{N}, 104^{\circ} \mathrm{E}$ ) were calculated for $200 \mathrm{Ma}$ in Pangaea B model.

$\left(^{* * * * *}\right)$ Rotation about an equatorial Euler pole to account for the displacement of the rotation (palaeomagnetic) axis with respect to core/mantle boundary (Cox and Hart, 1986).

Table IV. Absolute reconstructions of Eurasia in different Pangaea types and geographic coordinates of the sampling site at $250 \mathrm{Ma}$.

\begin{tabular}{cccccc}
\hline \hline $\begin{array}{c}\text { Pangaea } \\
\text { type }\end{array}$ & \multicolumn{3}{c}{$\begin{array}{c}\text { Absolute reconstruction } \\
\text { Euler poles }\end{array}$} \\
\hline \multicolumn{4}{c}{ Sampling site } \\
\hline Lat ${ }^{\circ} \mathrm{N}$ Long ${ }^{\circ} \mathrm{E}$ Angle $\left({ }^{\circ}\right)$ & Lat $^{\circ} \mathrm{N}$ Long ${ }^{\circ} \mathrm{E}$ \\
$\mathrm{A}$ & 58.37 & 85.38 & 66.89 & 62.46 & 63.08 \\
$\mathrm{~A} 2$ & 59.09 & 86.34 & 68.49 & 62.46 & 64.97 \\
$\mathrm{~B}$ & 42.15 & 71.89 & 45.89 & 62.46 & 36.10 \\
\hline
\end{tabular}

sition, using a stage Euler pole for the time span between 120 and $200 \mathrm{Ma}$ (lat $=31.38^{\circ} \mathrm{N}$, long $=$ $=3.4^{\circ} \mathrm{E}$, and an angle of counter clockwise rotation $=32.18^{\circ}$ ) calculated from the reconstruction parameters proposed for Africa by Morgan (1983). To perform the rotation of the plates rel- ative to hotspots from 200 to $250 \mathrm{Ma}$, we used Mongolian hotspot tracks that indicate that Siberia rotated $75^{\circ}$ in a clock wise direction from 280 to $130 \mathrm{Ma}$ about an Euler pole that is now located at $54^{\circ} \mathrm{N}, 104^{\circ} \mathrm{E}$ (Zonenshain et al., 1985). We transferred this pole to its geographic position at $200 \mathrm{Ma}$ in accordance with the different Pangaea models and using the hotspot frameworks of O'Neill et al. (2005) and Morgan (1983). Assuming Siberia rotated at a constant velocity, we proposed a rotation of $25^{\circ}$ of this continent between 200 and 250 Ma. The mean Siberian Trap PP and the plates were then rotated using the corresponding Euler poles for each Pangaea model accounting for the movement of Siberia relative to the hotspot track between 200 and $250 \mathrm{Ma}$.

Finally we calculated the displacement of the rotation (palaeomagntic) axis with respect to the hotspot frameworks for every Pangaea model and rotated all the plates about the equatorial 
Euler pole that belong to each case. The rotation poles to obtain the absolute reconstructions of the sampling site at $250 \mathrm{Ma}$ in different versions of Pangaea are listed in tables I, II and III. These poles are numbered in the sequential order that should be followed to perform the reconstructions. The cumulative rotation for all the movements described before has different reconstruction parameters for the different Pangaea models. In table IV are listed the Euler poles for the absolute reconstruction of Siberia in Pangaea A, A2 and $\mathrm{B}$ and the corresponding palaeogeographic coordinates of the sampling site at $250 \mathrm{Ma}$.

\section{Analysis of the transitional record and discussion}

The analysis was carried out comparing calculated and recorded data. The behaviour of the EMF is currently analyzed by plotting the VGPs as computed by palaeomagnetic direc- tions. However, a VGP is calculated assuming a dipole model, which is at variance with the strong non-dipolar field expected during a reversal (i.e. Gubbins and Coe, 1993). For this reason we have analyzed not only the computed VGPs but also their directions. The simulated data were determined according to the geographic coordinates of the measured site at 250 Ma for the different absolute reconstructions of Pangaea configurations using one of the models of Gubbins (1994).

Gubbins (1994) developed two models (E and $\mathrm{W}$ ) assuming the structure of the transitional field is substantially non-dipolar. Since the reversal recorded in the Siberian Trap Basalts is from reverse to normal and according to the path of its transitional VGPs, the model W was adopted to simulate the transitional record. Figures 2, 3, 4 and 5 compare modelled and recorded data; declinations, inclinations and palaeointensities are represented versus the latitude of the corresponding VGPs. Notice that unfortu-

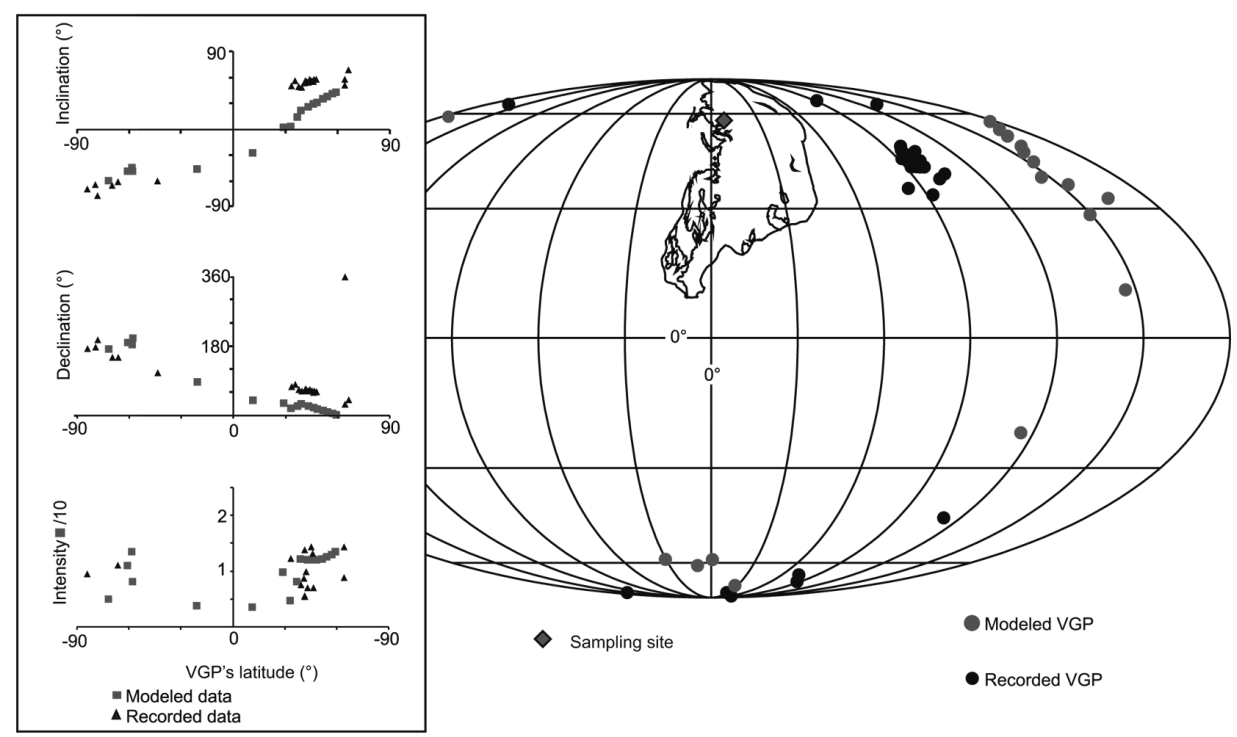

Fig. 2. Modelled and measured data of the polarity transition recorded in Siberian Trap Basalts. The data have just a palaeo-latitudinal correction according to the reconstruction parameter of Smethusrt et al. (1998) also used by Heunemann et al. (2004). The transitional modelled and recorded data form similar VGPs clusters however they do not agree. 

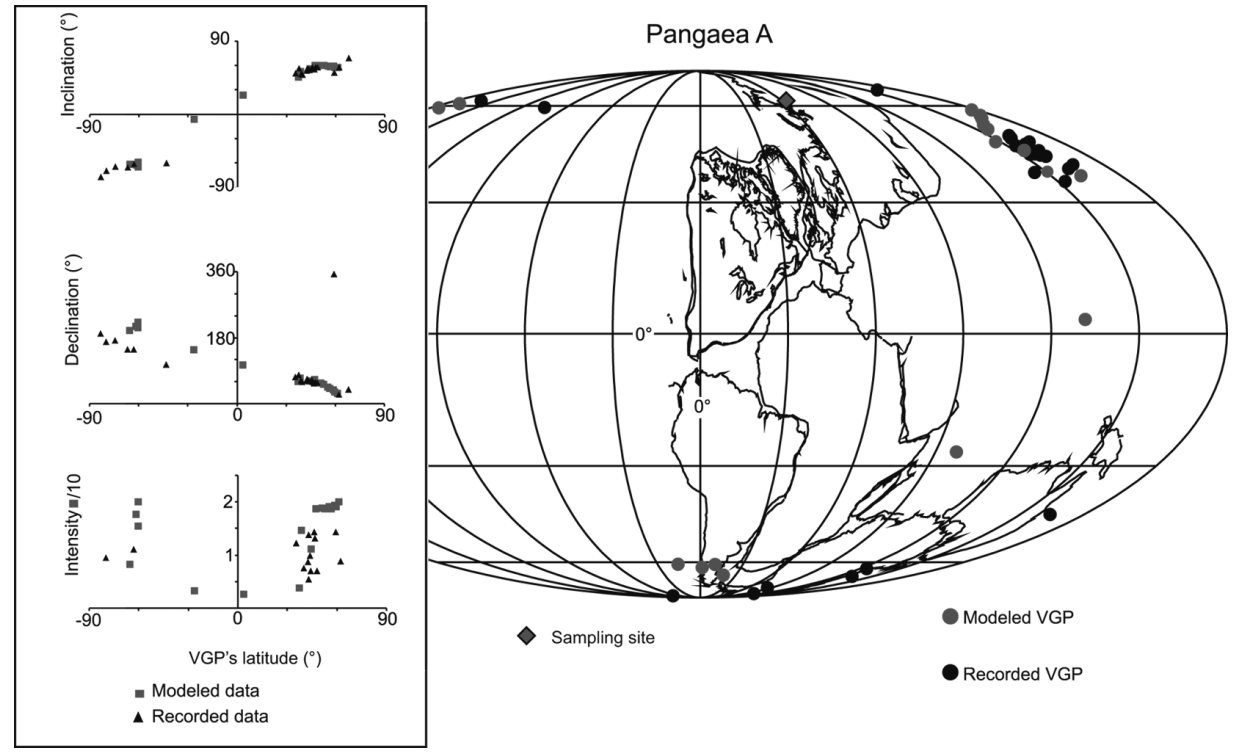

Fig. 3. Modelled and measured data of the polarity transition recorded in Siberian Trap Basalts in an absolute reconstruction of Pangaea type A configuration. The palaeo-latitudinal and palaeo-longitudinal corrections were done on the basis of hotspots frameworks and the mean Siberian Trap palaeopole. Notice the remarkable fit between both the modelled and recorded data.
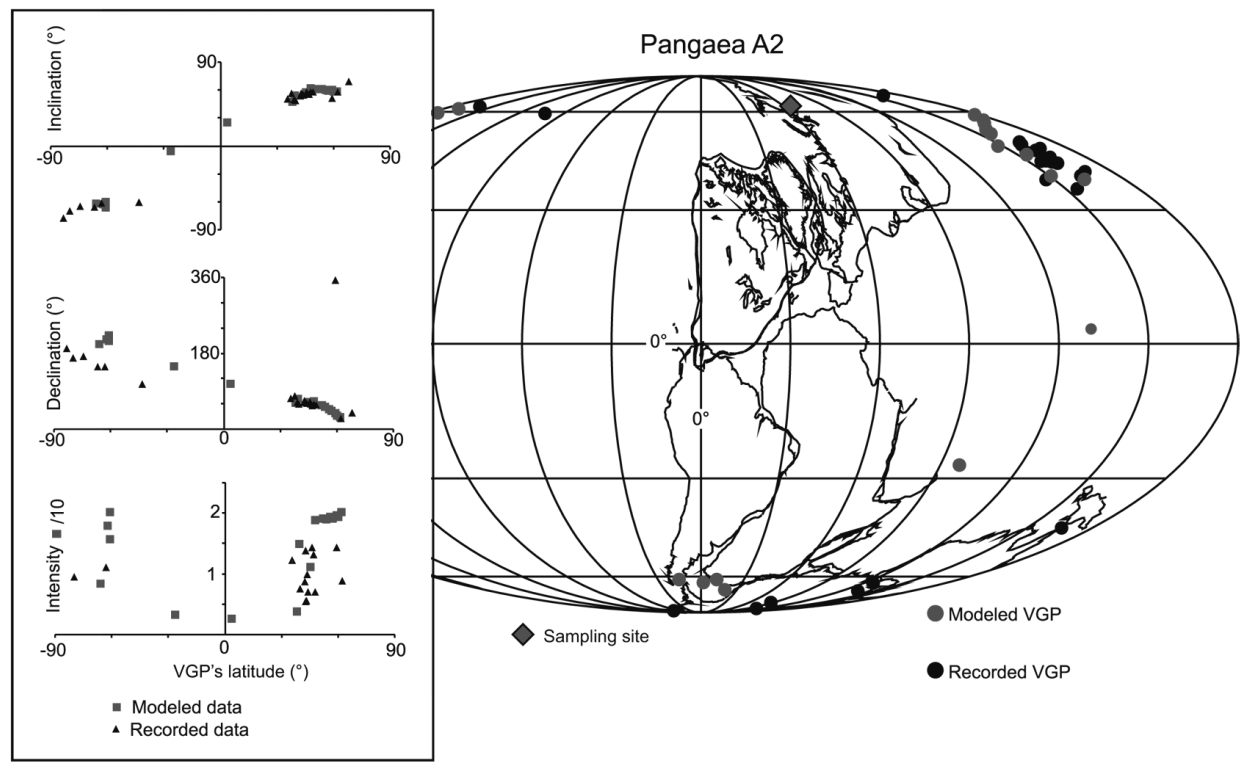

Fig. 4. Modelled and measured data of the polarity transition recorded in Siberian Trap Basalts in an absolute reconstruction of Pangaea type A2 configuration. The palaeo-latitudinal and palaeo-longitudinal corrections were done on the basis of hotspots frameworks and the mean Siberian Trap palaeopole. Notice the remarkable fit between both the modelled and recorded data as in fig. 3 . 


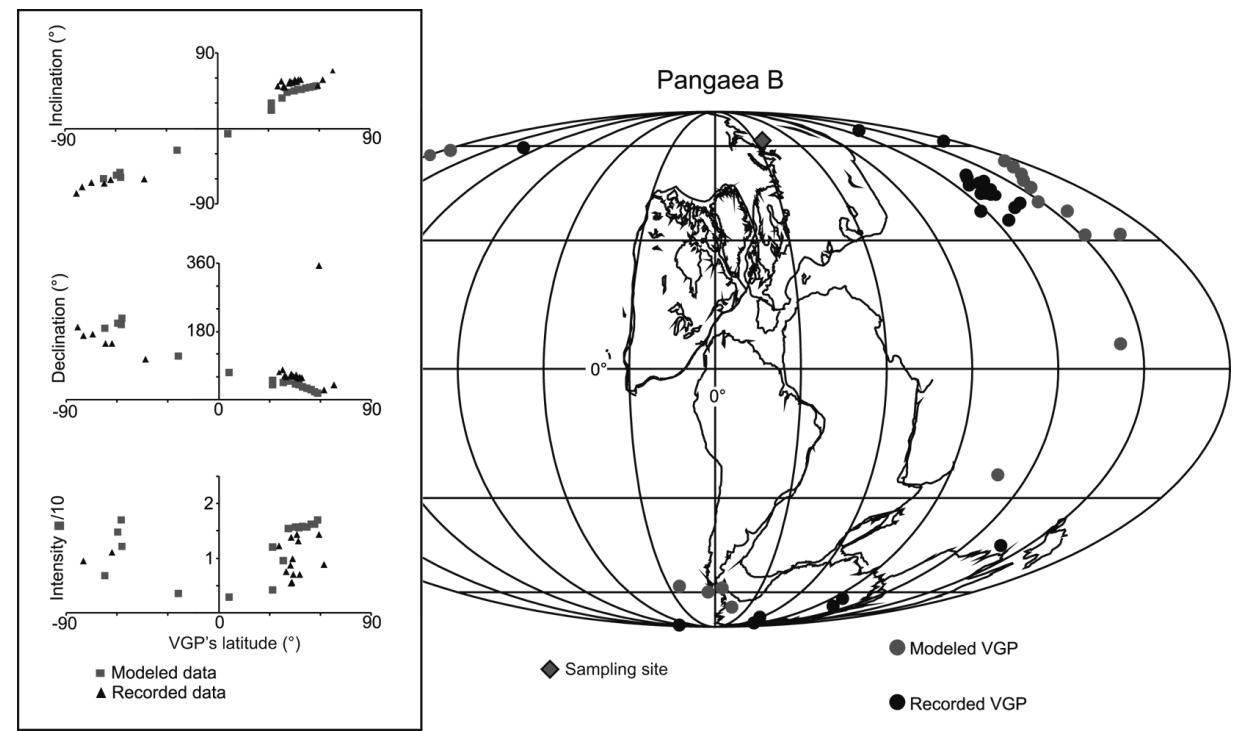

Fig. 5. Modelled and measured data of the polarity transition recorded in Siberian Trap Basalts in an absolute reconstruction of Pangaea type B configuration. The palaeo-latitudinal and palaeo-longitudinal corrections were done on the basis of hotspots frameworks and the mean Siberian Trap palaeopole. The modelled and recorded data are similar but they do not get as good fits as in A or A2 Pangaea models (figs. 3 and 4).

nately Heunemann et al. (2004) could not determine the corresponding palaeointensites for all the recorded palaeomagnetic directions.

Figure 2 shows the modelled and recorded data after the palaeo-latitudinal reconstruction of Smethrust et al. (1998) that was also used by Heunemann et al. (2004). Figures 3, 4 and 5 show the data in the different Pangaea models after the palaeo-latitudinal and palaeo-longitudinal reconstructions based on the mean Siberian Trap PP and the hotspot frameworks.

In all analyzed reconstructions there is a good fit between the modelled and recorded inclinations meanwhile the fit between the declinations is better for data which VGPs are in the north hemisphere.

In all the cases the modelled transitional data show a cluster of VGPs in the north hemisphere as that represented by the recorded transitional data. Both transitional clusters are better grouped in the models of Pangaea with palaeo-latitudinal and palaeo-longitudinal (absolute) reconstructions (compare fig. 2 with figs. 3, 4 and 5).
Pangaea A and A2 models show better fits between the transitional VGPs clusters than does the Pangaea B model (compare fig. 3 and 4 with fig. 5).

\section{Conclusions}

An analysis of the reversal recorded in the Siberian Trap Basalts suggests that similar features to those considered by Gubbins (1994) could have driven even reversals in the PermoTriassic.

In spite of the uncertainties associated with the hotspot frameworks and Pangaea configurations, the modelled and recorded data show a better fit when both palaeo-latitudinal and palaeolongitudinal reconstructions are considered.

Pangaea A and A2 show remarkable fits between the recorded and modelled clusters of transitional VGPs. Pangaea B, shows the best fit between the mean Siberian Trap PP and a Permo-Triassic Gondwana PP but has fewer geo- 
logical arguments in favour for $250 \mathrm{Ma}$ (Hallam, 1983; Irving, 2004) and does not show as good fit between the recorded and our modelled transitional clusters of VGPs.

\section{Acknowledgements}

We would like to thanks to CONICET (Consejo Nacional de Investigaciones Científicas y Técnicas, Argentina) and Universidad de Buenos Aires (Argentina) for supporting our investigations. Thanks also to Dr. Robert Ixer (Univeristy of Birmingham) for his suggestions after reading an early version of this paper. Comments of the anonymous referee are greatly appreciated.

\section{REFERENCES}

Besse, J. and V. Courtillot (2002): Apparent and true polar wander and the geometry of the geomagnetic field over the last $200 \mathrm{Myr}$, J. Geophys. Res., 107 (B11), 2300, doi: 10.1029/2000, JB 000050.

Briden, J.C., A.G. Smith and J.T. SAllomy (1971): The geomagnetic field in Permo-Triassic time, Geophys. J. R. Astron. Soc., 23, 101-118.

Bullard, E.C, J.E. EveritT and A.G. SMith (1965): The fit of continents around the Atlantic, Philos. Trans. R. Soc. London Ser. A, 258, 41-51.

Clement, B.M. (1991): Geographical distribution of transitional VGPs-Evidence for non-zonal equatorial symmetry during the Matuyama Brunhes geomagnetic reversal, Earth Planet. Sci. Lett., 104, 48-58.

CoE, R.S. and J.M.G. Glen (2004): The complexity of reversals, in Timescales of the Paleomagnetic Field (Am. Geophys. Un.), Geophys. Monogr. Ser., 145, 221-232.

Coe, R.S., L. Hongre and G.A. Glatzmaier (2000): An examination of simulated geomagnetic reversals from a palaeomagnetic perspective, Philos. Trans. R. Astron. Soc. London Ser. A, 358, 1141-1170.

Cox, A. V. and B.R. HART (1986): Plate Tectonics: How it Works (Blackwell Scientific, Palo Alto), pp. 392.

Engebretson, D.C., A. Cox and R.G. Gordon (1985): Relative motions between oceanic and continental plates in the Pacific Basin, Geol. Soc. Am., Spec. Pap. 206, pp. 59.

Glatzmaier, G.A., R.S. Coe, L. Hongre and P.H. Roberts (1999): The role of the Earth's mantle in controlling the frequency of geomagnetic reversals, Nature, 401, 885890 .

GuBBINS, D. (1987): Mechanism for geomagnetic polarity reversals, Nature, 326, 167-169.

GuBBINS, D. (1994): Geomagnetic polarity reversals: a connection with secular variation and core-mantle boundary interaction?, Rev. Geophys., 32, 61-83.

GubBINS, D. and R.S. COE (1993): Longitudinally confined geomagnetic reversal paths from non-dipolar transition fields, Nature, 362, 51-53.

Gurevitch, E.L., M. Westphal, J. Daragan-Suchov, H. FeinBerG, J.P. Pozzi and A.N. Khramov (1995): Paleomagnetism and magnetostratigraphy of the traps from Western Taimyr (Northern Siberia) and the Permo-Triassic crisis, Earth Planet. Sci. Lett., 136 (3-4), 461-473.

Gurevitch, E.L., C. Heunemann, V. Rad'ko, M. WestPhal, V. Bachtadse, J.P. Pozzi and H. FeinberG (2004): Palaeomagnetism and magnetostratigraphy of the Permian-Triassic northwest Central Siberian Trap Basalts, Tectonophysics, 379, 211-226.

Hallam, A. (1983): Supposed Permo-Triassic megashear between Laurasia and Gondwana, Nature, 301, 499-502.

Heunemann, C., D. Krása, H.C. Soffel, E. Gurevitch and V. BACHTADSE (2004): Directions and intensities of the Earth's magnetic field during a reversal: results from the Permo-Triassic Siberian Trap Basalts, Russia, Earth Planet. Sci. Lett., 218, 197-213.

HoffMAN, K.A. (1992): Dipolar reversal states of the geomagnetic field and core-mantle dynamics, Nature, 359, 789-794.

Irving, E. (2004): The case for Pangea B, and the intraPangean megashear, in Timescales of the Paleomagnetic Field (Am. Geophys. Un.), Geophys. Monogr. Ser., 145, 13-27.

KLITGORD, K.D. and H. Schouten (1986): Plate kinematics of the Central Atlantic, in The Geology of North America, The Western North Atlantic Region, edited by P.R. Vogt and H. Tucholke (Geol. Soc. Am., New York), 351-378.

Laj, C., A. Mazaud, R. Weeks, M. Fuller and E. HerRERO-BERVERA (1991): Geomagnetic reversal paths, Nature, 351, 447.

LANGereis, C.G., A.A. van Hoof and P. RochetTe (1992): Longitudinal confinement of geomagnetic reversal paths as a possible sedimentary artefact, Nature, 358, 226-229.

Love, J.J. (1998): Paleomagnetic volcanic data and geometric regularity of reversals and excursions, J. Geophys. Res., 103, 12,435-12,452.

McElhinny, M. (2004): Geocentric axial dipole hypothesis: a least squares perspective, in Timescales of the Paleomagnetic Field (Am. Geophys. Un.), Geophys. Monogr. Ser. , 145, 1-12.

McFadden, P. L. and F.J. Lowes (1981): The discrimination of mean directions drawn from Fisher distributions, Geophys. J. R. Astron. Soc., 67, 19-33.

Morel, P. and E. Irving (1981): Paleomagnetism and the evolution of Pangea, J. Geophys. Res., 86, 1858-1872.

Morgan, W.J. (1983): Hotspot tracks and early rifting of the Atlantic, Tectonophysics, 94, 123-139.

Muttoni, G., D.V. Kent and J.E.T. Channell (1996): Evolution of Pangea, paleomagnetic constraints from the Southern Alps, Earth Planet. Sci. Lett., 140, 97-112.

Muttoni, G., D.V.Kent, E. Garzani, P. Brack, N. AbraHAMSEN and M. GAETANI (2003): The mid-Permian revolution from Pangea 'B' to 'A', Earth Planet. Sci. Lett., 215, 379-394.

O'Neill, C., D. Müller and B. Steinberger (2005): On the uncertainties in hot spot reconstructions and the significance of moving hot spot frames, Geochem. Geophys. Geosys., 6, 1-35. 
Prévot, M. and P. CAMPs (1993): Absence of preferred longitudinal sectors for poles from volcanic records of geomagnetic reversals, Nature, 366, 53-57.

Prévot, M., N. Roberts, J. Thompson, L. FAynot and M. PERRIN (2003): Revisiting the Jurassic geomagnetic reversal recorded in the Lesotho Basalt (Southern Africa), Geophys. J. Inter, 155, 367-378.

Rakotosolofo, N.A., J.A. TAit, V. CARlotto and J. CÁrDENAS (2005): Palaeomagnetic results from the Early Permian Copacabana Group, Southern Peru: implication for Pangaea palaeogeography, Tectonophysics, 413, 287-299.

Rochette, P. and D. VAndamme (2001): Pangea B: an artefact of incorrect paleomagnetic assumptions?, Ann. Geofis., 44 (3), 649-658.

Schettino, A. and C.R. Scotese (2005): Apparent polar wander paths for the major continents (200 Ma to the present day): a palaeomagnetic reference frame for global plate tectonic reconstructions, Geophys. J. Inter., 163, 727-759.

Smethurst, M.A., A.N. Khramov and T.H. Torsvik (1998): The Neoproterozoic and Palaeozoic data for the Siberina Platform: from Rodinia to Pangea, EarthSci. Rev., 43, 1-24.

Smith, A.G. and R.A. Livermore (1991): Pangea in Permian to Jurassic time, Tectonophysics, 187, 135-179.

TorcQ, F., J. Besse, D. Vaslet, J. Marcoux, L.E. Ricou, M. Halawani and M. BasaHel (1997): Paleomagntic results from Saudi Arabia and the Permo-Triassic Pangea configuration, Earth Planet. Sci Lett., 148, 553-567.

Torsvik, T.H. and T.B. Andersen (2002): The Taimyr Fold Belt, Arctic Siberia: timing of pre-fold remagnetisation and regional tectonics, Tectonophysics, 352, 335-348.

TORSVIK, T.H. and R. VAN DER Voo (2002): Refining Gondwana and Pangea palaeogeography: estimates of Phanerozoic non-dipole (octupole) fields, Geophys. J. Inter., 151, 771-794.

Torsvik, T.H., R. VAN DER Voo, J.G. MeERT, J. Mosar and H. WALDERHAUG (2001): Reconstructions of the continents around the North Atlantic at about the 60th parallel, Earth Planet. Sci. Lett., 187, 55-69.
TORSVIK, T.H, R. VAN DER VOO and T.F. REDFIELD (2002): Relative hotspot motions versus true polar wander, Earth Planet. Sci. Lett., 202 (2), 185-200.

VAN DER VoO, R. (1990): Phanerozoic paleomagnetic poles from Europe and North America and comparisons with continental reconstructions, Rev. Geophys., 28, 167206.

VAN DER Voo, R. and R.B. FRENCH (1974): Apparent polar wandering for the Atlantic bordering continents: Late Carboniferous to Eocene, Earth Sci. Rev., 10, 99-119.

VAN DER VoO, R. and T.H. TORSVIK (2001): Evidence for late Paleozoic and Mesozoic non-dipole fields provides an explanation for the Pangea reconstruction problems, Earth Planet. Sci. Lett., 187, 71-81.

VAN DER Voo, R. and T.H. TORSVIK (2004): The quality of the European Permo-Triassic paleopoles and its impact on Pangea reconstructions, in Timescales of the Paleomagnetic Field (Am. Geophys. Un.), Geophys. Monogr. Ser., 145, 29-42.

VAn Der Voo, R., F.J. MAuK and R.B. French (1976): Permian Triassic continental configurations and the origin of the Gulf of Mexico, Geology, 4, 177-180.

VAN ZiJl, J.S.V., K.W.T. Graham and A.L. Hales (1962): The palaeomagnetism of the Stormberg lavas of South Africa 1: evidence for a genuine reversal of the Earth's field in Triassic-Jurassic times, Geophys. J. R. Astron. Soc., 7, 23-39.

VizÁN, H. and M.A.VAn Zele (1995): Analysis of a lower Jurassic geomagnetic reversal based on a model that relates transitional fields to variations of flux on the core surface, Studia Geophys. Geod., 39, 177-188.

Wegener, A. (1922): Origin of Continents and Oceans, English translation of 3rd edition by J.G.A. SKERL (Methuen), pp. 1-212.

Zonenshain, L.P., M.I. KuZMin and M.V. Kononov (1985): Absolute reconstructions of the Paleozoic oceans, Earth Planet. Sci. Lett., 74, 103-116.

(received April 3, 2006; accepted June 1, 2007) 